Comment

Although there have been many studies of aggregation of platelets after stroke, ${ }^{3}$ few data exist on aggregation immediately before stroke. The patient reported on here had hyperaggregable platelets before the stroke and hypoaggregable platelets (and a lower platelet count) after it. The hyperaggregable platelets may possibly have participated in the formation of thrombus and not been available in the circulation after the stroke; alternatively, natural protective mechanisms may have operated to reduce the aggregability of platelets.

Although aggregation of platelets was reduced after the stroke, it continued to be resistant to the inhibitory effects of epoprostenol. Resistance to inhibitory prostaglandins in thrombocythaemia has recently been reported by others. ${ }^{4}$ That this abnormality was present both before and after stroke in our patient suggests that they are not major determinants of the extent of aggregation of platelets in whole blood. Nevertheless, the resistance of aggregation to inhibition by epoprostenol may be relevant in vivo.

Preston et al found that patients with high platelet counts and neurological symptoms improved considerably with treatment with aspirin and dipyridamole. $^{5}$ The fact that in our patient the acute stroke occurred only 16 days after treatment was withdrawn may be important; aspirin and dipyridamole may have been providing protection by reducing the aggregability of platelets.

1 Fox SC, Burgess-Wilson M, Heptinstall S, Mitchell JRA. Platelet aggregation in whole blood determined using the Ultra-Flo 100 whole blood platelet counter. Thromb Haemost 1982;48: determ.

2 Andrews NP, Broughton Pipkin F, Heptinstall S. Blood platelet behaviour in mothers and neonates. Thromb Haemost 1985;53:428-32.

3 Heptinstall S, Mitchell JRA. Platelets and thrombosis. In: Biggs R, Rizza CR, eds. Human blood coagulation, haemostasis and thrombosis. 3rd ed. Oxford: Blackwell, 1984:380-414

4 Cortelazzo S, Castagna D, Galli M, Barbui T, de Gaetano G. Increased response to arachidonic acid and U-46619 and resistance to inhibitory prostaglandins in patients with chronic myeloproliferative disorders [Abstract]. Thromb Haemost 1987;58:159.

5 Preston FE, Martin JF, Stewart RM, Davies-Jones GAB. Thrombocytosis, circulating platelet aggregates, and neurological dysfunction. Br Med f 1979;ii:1561-3.

(Accepted 16 December 1987)

Department of Medicine, University Hospital, Queen's Medical Centre, Nottingham NG7 2UH

S HEPTINSTALL, BSC, PHD, senior lecturer

$S$ R COCKBILL, BSC, senior medical laboratory scientific officer

M E BURGESS-WILSON, FIMLS, senior medical laboratory scientific officer

EW JONES, MD, MRCP, lecturer in medicine

Correspondence to: Dr Heptinstall.

\section{Alcohol intoxication and severity of injury in victims of assault}

Though an association between alcohol intoxication and aggression has been generally established, ${ }^{1}$ surprisingly little evidence of direct cause and effect exists with regard to the increasing problem of violence in inner cities. ${ }^{2}$ Further, although victims of many crimes of violence have been found to be intoxicated, ${ }^{34}$ data linking the degree of intoxication to the severity of injury are not available. We therefore investigated the association.

\section{Patients, methods, and results}

We interviewed and examined 470 consecutive victims of assault who attended an inner city accident and emergency service in 1986. Their reported intake of alcohol in the 12 hours immediately before the assault was recorded by trained interviewers. Blood ethanol concentrations corresponded to this alleged intake $(r=0.699)$ in the 362 patients $(77 \%)$ who consented to testing. The rate of admission to hospital was not significantly different in patients who consented to the investigation and those who did not; the patients who did not consent may have suspected that drug abuse might be detected or the police informed, despite reassurances to the contrary. We compiled an index of the severity of injuries in our patients and related this to the need for admission to hospital by using a logistic regression model because a suitable scale for categorising injuries in victims of assault was not available.

The categories of the index were as follows: category I = one haematoma or one laceration; II =multiple haematomas or lacerations, or both; III=one fracture; $\mathrm{IV}=$ one fracture and haematomas or lacerations, or both; and $\mathrm{V}=$ more than one fracture.

Of the 126 patients in category I, eight $(6 \%)$ were admitted to hospital, compared with $19(9 \%)$ of the 213 in category II, eight $(28 \%)$ of the 29 in category III, $25(35 \%)$ of the 71 in category IV, and $23(75 \%)$ of the 31 in category V. The index significantly improved the fit compared with the model that assumed a constant chance of admission to hospital $(\mathrm{p}<0.01)$ and also facilitated investigation of the link between the degree of intoxication and the number of injuries sustained. The index was therefore preferable to admission to hospital as an indicator of severity of injury. Interestingly, recent intake of alcohol alone was also a reasonably accurate indicator of the need for admission $(p<0.05)$, though neither this nor the injury severity scale was used to assess patients in this department.

The table shows the number of patients in each category of injury and recent alcohol consumption. Patients who reported abstinence tended to have more

Severity of injury and consumption of alcohol. Figures are numbers of patients

\begin{tabular}{lrrrrrc}
\hline \multirow{2}{*}{$\begin{array}{l}\text { Recent consumption } \\
\text { alcohol (units }\end{array}$} & \multicolumn{7}{c}{ Severity of injury (categoryt) } \\
\cline { 2 - 7 } & I & II & III & IV & V & Total \\
\hline 0 & 54 & 54 & 14 & 20 & 5 & 147 \\
$1-10$ & 49 & 96 & 9 & 28 & 17 & 199 \\
$>10$ & 23 & 63 & 6 & 23 & 9 & 124 \\
\hline Total & 126 & 213 & 29 & 71 & 31 & 470 \\
\hline
\end{tabular}

$\star$ One unit $=1 / 2$ pint of beer or lager, one measure of spirits, one glass of wine. II $=$ One haematoma or laceration; II = multiple haematomas or lacerations, or both; III =one fracture; IV =one fracture and haematomas or lacerations, or both; $V=$ multiple fractures. $\chi^{2}$ (Yates's correction $)=25 \cdot 5, \mathrm{df}=10, \mathrm{p}<0.05$.

minor (category I) and fewer severe (category V) injuries whereas drinkers who had consumed more than 10 units of alcohol tended to have more severe (category IV) injuries. Only $23(18 \%)$ of those with category I injury had consumed more than 10 units of alcohol, compared with nine $(29 \%)$ of those with category $\mathrm{V}$ injury. In addition, multiple injuries (categories II, IV, and V) were more likely and single injuries (categories I and III) less likely in drinkers than non-drinkers. Of the patients with single injuries, $68(44 \%)$ were abstainers, but only $79(25 \%)$ of those who sustained multiple injuries had abstained.

\section{Comment}

This link between consumption of alcohol by a victim of assault and more serious injury and multiple wounds may arise because aggression and loss of judgment induced by alcohol in the victims prolongs violence or simply because intoxicated victims are less able to avoid blows during an assault. Our data showed that abstinence made severe or multiple injuries in assault less likely and suggested that binge drinking, when more than 10 units were consumed, conferred greater risk of severe injury.

1 Department of Health and Social Security. Drinking sensibly. London: HMSO, 1981

2 Walmsley R. Personal violence. London: HMSO, 1986:16. (Home Office research study No 89.)

3 Light R. Alcohol and crime. Police Review 1986;95:734-5.

4 Shepherd JP, Shapland M, Irish M, Scully C, Leslie IJ. Assault: characteristics of victims attending an inner-city hospital. Injury (in press).

(Accepted 27 fanuary 1988)

University Department of Oral Medicine, Surgery, and Pathology, Bristol Dental School and Hospital, Bristol BS1 2LY

JONATHAN SHEPHERD, PHD, FDSRCS, consultant senior lecturer in oral and maxillofacial surgery

MARGARET IRISH, BSC, statistician

CRISPIAN SCULLY, PHD, MRCPATH, professor

Department of Orthopaedic and Traumatic Surgery, Bristol Royal Infirmary, Bristol BS2 8HW

IAN LESLIE, MCHORTH, FRCS, consultant orthopaedic surgeon

Correspondence to: Dr Shepherd. 